\title{
ОСНОВНЫЕ ФОРМЫ МИГРАЦИИ МЕТАЛЛОВ В ПРИСУТСТВИИ ГУМИНОВЫХ ВЕЩЕСТВ В СОДОВЫХ ОЗЕРАХ ВОСТОЧНОГО ЗАБАЙКАЛЬЯ
}

\author{
Федоров И.А., Борзенко С.В. \\ Институт природных ресурсов, экологии и криологии Сибирского отделения Российской академии наук, Чита, \\ Poccuя, E-mail:fedorowia@gmail.com,svb_64@mail.ru
}

\begin{abstract}
АННОТАЦИЯ: В работе рассмотрены результаты химических исследований и термодинамического моделирования состава природных вод содовых озер Восточного Забайкалья, определены основные формы нахождения некоторых металлов. Установлено, что основным барьером на пути концентрирования в озерах для основных катионов выступают минералы, с которыми вода находится в равновесии и даже пересыщена ими. Количество связанных в комплексы металлов и их положения в рядах определяются содержанием органического вещества, свойствами этих металлов, а также основными геохимическими параметрами среды.
\end{abstract}

\section{1. ВВЕДЕНИЕ}

Вопросы комплексообразования и строения координационных соединений металлов с гумусовым веществом (ГВ) в водных экосистемах занимают важное место и являются достаточно изучаемой областью гидрогеохимии [2]. Обладая макролигандными свойствами, ГВ вносит существенный вклад в инактивацию большинства металлов снижая их токсичность и биодоступность [3]. Селективность ионов металлов позволяет ранжировать их по склонности к сорбции ГВ в зависимости от физико-химических параметров среды их нахождения [6]. В этом плане проведена огромная работа по установлению значений констант устойчивости ГВ с металлами, форм их нахождения в водах в зависимости от природной климатической зоны, определены ряды устойчивости Ме-ГВ в болотно-озерных системах [7]. Между тем, для рассматриваемого региона подобных исследований ранее не проводилось.

Современные термодинамические модели [5], например, NICA model, на использовании которых основаны компьютерные комплексы для моделирования, позволяют с большой достоверностью моделировать биогеохимические процессы, протекающие в системе вода - горная порода - органическое вещество - газ и определять роль ГВ в рассеивании или концентрировании металлов в природных водах.

Основная цель настоящей работы заключается в выявлении с помощью термодинамических расчетов основных форм миграции некоторых металлов и ранжировании по степени связывания их фульвовыми (ФК) и гуминовыми (ГК) кислотами в водах некоторых содовых озер Восточного Забайкалья.

\section{2. ОБЪЕКТЫ И МЕТОДЫ}

Объекты исследования - минеральные озера Восточного Забайкалья: Цаган-Нур, БаймБулак, Цаган-Нор, Зун-Торей, Гонга-Нур, Хара-
Торум, Харанор, Холбон, Доронинское. Химико-аналитический анализ выполнялся общепринятыми методами [4]. Концентрации металлов устанавливались методами атомной спектрометрии. Потенциометрическими методами определялись $\mathrm{pH}, \mathrm{Eh}, \mathrm{F}^{-}$. Титриметрией $-\mathrm{CO}_{2}$, $\mathrm{CO}_{3}{ }^{2-}, \mathrm{HCO}_{3}^{-}, \mathrm{SO}_{4}^{2-}, \mathrm{Cl}^{-}$. Фотометрическими методами устанавливались количества $\mathrm{Si}, \mathrm{P}, \mathrm{S}^{2}$, ГК, ФК и химическое потребление кислорода (ХПК), по которому оценивали содержание в водах органического углерода.

Формирование комплексов с органическими веществами, в частности с ФК и ГК, рассматривалось для основных катионов $\mathrm{Ca}, \mathrm{Mg}, \mathrm{Na}, \mathrm{K}$ и некоторых микроэлементов $\mathrm{Fe}, \mathrm{Mn}, \mathrm{Ni}, \mathrm{Co}, \mathrm{Cu}$, $\mathrm{Zn}, \mathrm{Pb}, \mathrm{Al}$. Расчет форм миграции проводился с использованием компьютерной программы MINTEQ (версия 3.1) и встроенной базы данных констант устойчивости комплексов металлов (Generic NICA-Donnan model). Также учитывалось протекание конкурентных реакций, таких как реакции образования гидроксидных, гидрокарбонатных, сульфатных, хлоридных комплексов металлов.

\section{3. РЕЗУЛЬТАТЫ ИССЛЕДОВАНИЯ И ОБСУЖДЕНИЕ}

По пространственному положению все озера относятся к Онон-Борзинской лимнической системе. Все они бессточные, повышенная соленость их вызвана испарительным концентрированием вод. Согласно делению вод по минерализации, пять из девяти озер относятся к солоноватым - оз. Байм-Булак $(2,49$ г/л), оз. Хара-Торум $(2,67$ г/л), оз. Харанор $(5,61$ г/л), оз. Цаган-Нор (5,73 г/л), и оз. Гонга-Нур (6,49 г/л); остальные к соленым - оз. Цаган-Нур (12,9 г/л), оз. ЗунТорей $(13,4$ г/л), оз. Доронинское $(22,5$ г/л) и оз. Холбон (28,4 г/л). Величина рН в данных озерах колеблется от 9,18 до 9,75. Все они относятся к 
содовому типу (по Курнакову-Валяшко) [1]. В сумме анионов доминируют карбонатный комплекс $\left(\mathrm{CO}_{3}{ }^{2-}+\mathrm{HCO}_{3}{ }^{-}\right)$и хлорид-ион $\mathrm{Cl}^{-}$. Сульфаты в значимых количествах (более 20 мг-экв. \%) присутствуют в двух озерах: Харанор и ГонгаНур. Среди катионов основным является натрий. Доля кальция и магния становится заметнее в менее минерализованных и щелочных озерах (оз. Байм-Булак и Гонга-Нур). В широких границах изменяются концентрации металлов Максимальный диапазон характерен для $\mathrm{Fe}$ и $\mathrm{Zn}$, coдержания которых варьируют в пределах нескольких математических порядков (2,5-382,0 мг/л и 0,78-15,41 мг/л соответственно). В меньших масштабах изменяются концентрации Со и $\mathrm{Pb}$ (0,2-2 мг/л и 0,1-9,4 мг/л соответственно). Содержание растворенного $\mathrm{C}_{\text {орг }}$ варьирует от 15,5 до 108,2 мг/л, определенных в оз. Харанор и о3. Доронинское соответственно. ГВ представлены преимущественно ФК, с содержанием от 7,13 (оз. Байм-Булак) до 98,3 мг/л (оз. ХараТорум). В меньших количествах присутствуют ГК с концентрацией от 1,6 мг/л (оз. Байм-Булак) до 6,74 г/л. (оз. Холбон). По большинству озер с ростом солености вод увеличиваются абсолютные содержания основных ионов $\mathrm{Na}^{+}, \mathrm{CO}_{3}{ }^{2-}$, $\mathrm{HCO}_{3}{ }^{-}, \mathrm{Cl}^{-}$и $\mathrm{C}_{\text {орг }}$, напротив, $\mathrm{SO}_{4}{ }^{2-}$ снижаются; в отношении $\mathrm{K}, \mathrm{Mg}$ и Са зависимости отсутствуют (рис. 1).

Расчеты показали, что относительно низкая степень связывания металлов с ГВ отмечается у основных катионов, присутствующих в растворе в виде ионов и комплексов с неорганическими лигандами. Увеличение содержаний ГВ в растворе способствует накоплению $\mathrm{Mg}$-ГВ и Са-ГВ в количестве до 18 и 31 мол. \% соответственно. Для этих металлов характерна тенденция увеличения долей гуминового комплекса с ростом солености вод. Основными же органическими формами их миграции являются комплексы с фульвокислотами, наибольший процент которых приходится на менее минерализованные озера. Основными формами миграции ионов натрия и калия являются $\mathrm{Me}^{+}$, содержания которых составляют более 90 мол. \%, и только в соленом 03. Доронинское $\mathrm{Na}$ находится (до 20 мол. \%) в виде $\mathrm{Na}-\mathrm{CO}_{3}-\mathrm{HCO}_{3}$.

Стронций и барий обладают низким сродством к ГВ. Наиболее распространены они в форме катионов $\mathrm{Me}^{2+}$. В наиболее соленых и щелочных условиях доли $\mathrm{Me}^{2+}$ и $\mathrm{Me}-\mathrm{CO}_{3}-\mathrm{HCO}_{3}$ находятся в сопоставимых количествах. Максимальные содержания бария и стронция в виде органически связанных с ГК- и ФК-лигандами достигают 8,36 и 10,03 мол. \% соответственно. Тем не менее, барий, подобно магнию и кальцию, при низкой минерализации $(2,5$ г/л) связан в комплексы с ФК, при высокой $(28,4$ г/л) - в комплексы с ГК, а для стронция повсеместно преобладает доля его фульватного ассоциата.
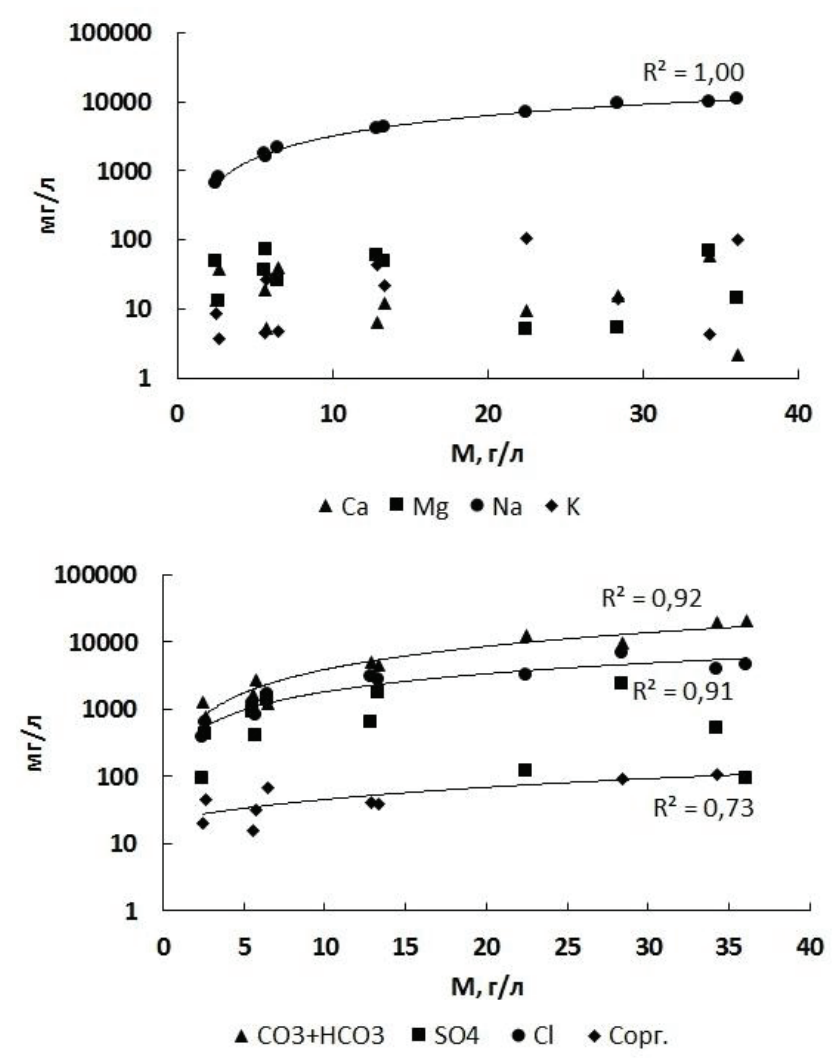

Рис. 1. Распределение содержаний основных ионов и органического углерода относительно минерализации вод

В меньшей степени по сравнению с остальными микроэлементами образование органических комплексов характерно для алюминия, который присутствует в озерных водах более чем на $99 \%$ в виде гидроксильного иона $\mathrm{Al}(\mathrm{OH})_{4}^{-}$. На долю его растворенного фульфатного ассоциата приходятся десятые доли процента, еще ниже содержания гуминового. Марганец мигрирует в основном в виде карбонатного комплекса $\mathrm{Mn}-\mathrm{CO}_{3}-\mathrm{HCO}_{3}$ и $\mathrm{Mn}^{2+}$. Максимальная степень его присутствия в органически связанной форме Mn-ГК и Мn-ФК достигает всего 6 мол. \%, при этом с ростом солености вод доля существенно снижается. В отношении основных форм миграции никеля проявляется аналогичная картина, но по сравнению с марганцем он в больших количествах находится в органической форме (среднее 30,2 мол. \%). Существенная разница между содержаниями Ni-ФК

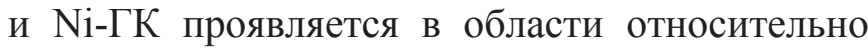
низких и высоких значений солености и $\mathrm{pH}$. 
Максимальная степень связывания с ГВ характерна для $\mathrm{Cu}$, присутствующей в растворе преимущественного в форме Сu-ФК $(64,8-94,3$,

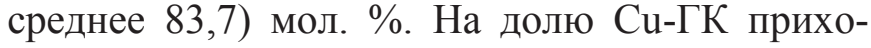
дится всего от 5,7 до 35,3 , при среднем 16,3 мол. \%. При этом относительное содержание меди в виде неорганических соединений, в частности $\mathrm{Cu}-\mathrm{CO}_{3}-\mathrm{HCO}_{3}$, остается несоизмеримо малым (менее 1 мол. \%). Имеет место зеркально-симметричный характер распределения относительных содержаний $\mathrm{Cu}-\Phi К$ и Сu-ГК в зависимости от основных геохимических параметров среды (рис. 2), с минимальной разницей их соотношений при $\mathrm{pH}$ 9,42 и минерализации 2,67 г/л. Как по максимальным, так и по средним оценкам, $\mathrm{Fe}^{3+}$ по сравнению с $\mathrm{Cu}^{2+}$ в меньших объемах мигрирует в виде Fе-ФК (от 43,9 до 88,8 мол. \%, при среднем 75,7 мол. \%), но больше в виде Fе-ГК (от 10,2 до 56,1 мол. \%, в среднем 23,8 мол. \%). В распределении его органических соединений зависимости аналогичны $\mathrm{Cu}(\mathrm{II})$, за исключением того, что в установленном диапазоне $\mathrm{pH}$ и минерализации преобладает доля гуминового комплекса (рис. 2).
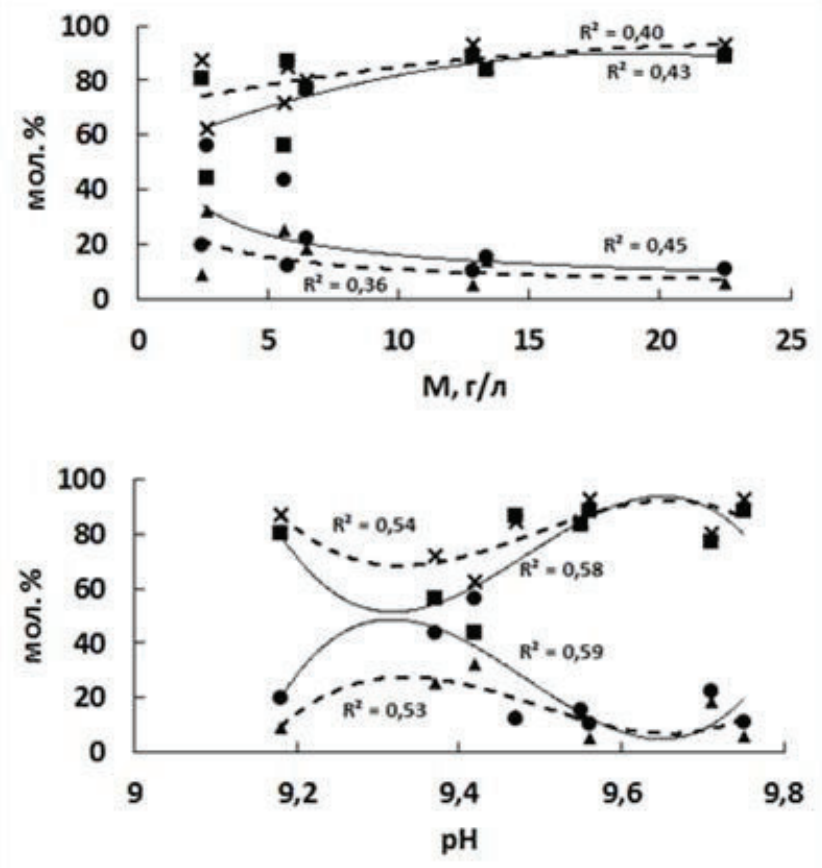

- $\mathrm{Fe}-\mathrm{rK}=\mathrm{Fe}-\Phi \mathrm{A} \Delta \mathrm{Cu}-\mathrm{rK} \times \mathrm{Cu}$-ФK

Рис. 2. Распределение основных органических форм $\mathrm{Cu}$ (штриховые линии) и $\mathrm{Fe}$ (сплошные линии) относительно минерализации и $\mathrm{pH}$ озерных вод

Кобальт, цинк и свинец по значимости связывания лигандами ГВ следуют за медью и железом, средние содержания Ме-ФК достигают $64,3,60,6$ и 62,7 мол. \% соответственно. По средним оценкам содержание Ме-ГК для первых двух элементов составляет около 24,9 и 24,0 мол. \% соответственно, для свинца увеличивается до 35,7 мол. \%.

Очевидно, что металлы в силу своих индивидуальных свойств обладают различным сродством к связыванию ГВ, отсюда в содовых озерах их можно ранжировать по степени связывания в следующий ряд: $\mathrm{Cu}^{2+}>\mathrm{Fe}^{3+}>\mathrm{Co}^{2+}>\mathrm{Pb}^{2+}>$ $\mathrm{Zn}^{2+}>\mathrm{Ni}^{2+}>\mathrm{Ca}^{2+}>\mathrm{Mg}^{2+}>\mathrm{Ba}^{2+}>\mathrm{Sr}^{2+}>\mathrm{Mn}^{2+}>$ $\mathrm{K}^{+}>\mathrm{Na}^{+}>\mathrm{Al}^{3+}$. По объему сорбированных гуминовыми кислотами металлов селективность проявляется в следующем порядке: $\mathrm{Pb}^{2+}>\mathrm{Co}^{2+}$ $>\mathrm{Zn}^{2+}>\mathrm{Fe}^{3+}>\mathrm{Cu}^{2+}>\mathrm{Ni}^{2+}>\mathrm{Ca}^{2+}>\mathrm{Mg}^{2+}>\mathrm{Sr}^{2+}>$ $\mathrm{Ba}^{2+}>\mathrm{Al}^{3+}>\mathrm{K}^{+}, \mathrm{Na}^{+}$. Для шести первых элементов процент сорбции по средним оценкам составляет от 60 до 35 мол. \%. Согласно термодинамическим расчётам такие ионы как $\mathrm{Ca}, \mathrm{Mg}$, $\mathrm{Sr}, \mathrm{Ba}, \mathrm{Al}$ в меньшей степени подвержены процессам сорбции, чем тяжелые металлы. Их доля, сорбированная ГВ, составляет от 0,3 до 14 мол. \%. В то же время, относительно низкие их концентрации в водах могут объясняться вторичным минералообразованием.

Исходя из расчетов, в озерах возможно формирование широкого спектра хемогенных карбонатов (кальцит и ватерит, доломит, моногидрокальцит, несквегонит и гидромагнезит, стронцианит, витерит, сидерит, родохрозит) Среди карбонатов Na-группы отмечается возможность насыщения наиболее минерализованных вод гейлюсситом, но при этом значение степени насыщения остается низким (не превышает 0,69 ). В виду относительно невысокой солености озер не достигается равновесие с основными Na-минералами - натроном, термонатритом, мирабилитом и др., поэтому натрий, в отличие от кальция, магния, стронция и бария, накапливается в растворе.

\section{4. ЗАКЛЮЧЕНИЕ}

Таким образом, из расчетов следует, что основными формами миграции $\mathrm{Cu}, \mathrm{Fe}, \mathrm{Pb}, \mathrm{Ni}$ и $\mathrm{Co}$ в минерализованных содовых озерах являются их органические комплексы с ГВ. Для $\mathrm{Ca}, \mathrm{Mg}$, $\mathrm{K}, \mathrm{Mn}, \mathrm{Ba}, \mathrm{Sr}, \mathrm{Al}$ доля присутствия их в виде Ме-ГВ несоизмеримо мала в сравнении с неорганическими ассоциатами. Основным барьером на пути концентрирования в водах для основных катионов выступают минералы, с которыми воды находятся в равновесии и даже пересыщены ими.

Как показали расчеты, количество металлов, мигрирующего в составе органического веще- 
ства, и положение их в рядах определяются как содержанием органического вещества, так и геохимическими параметрами среды - $\mathrm{pH}$ и соленостью вод, а также свойствами самих металлов.

Между тем необходимо отметить, что любые незначительные изменения значений основных параметров (Eh, температура и др.) могут привести к процессу десорбции и росту содержаний растворенных форм тяжелых металлов в водах. В то время как вторичное минералообразование - процесс термодинамически более устойчивый.

Исследование выполнено при финансовой поддержке РФФИ в рамках научного проекта № 18-05-00104 «Геохимия озер Восточного Забайкалья: гидрогеохимические условия формирования и их минеральные ресурсыл».

\section{СПИСОК ЛИТЕРАТУРЫ}

1. Валяшко М.Г. Классификационные признаки соляных озер // Труды Всесоюзного Научноисследовательского института галургии. - Л.-М., 1952. Вып. 23. - С. 13-19.

2. Дину М.И., Моисеенко Т.И., Кремлева Т.А. Влияние процессов комплексообразования гумусовых ве- ществ на формы миграции металлов в природных водах зон северной тайги и лесостепи Тюменской области // Вестник Тюменского государственного университета. 2012. - № 12. - С. 71-79.

3. Перминова И.В., Данченко Н.Н., Ященко Н.Ю., Лебедева Г.Ф., Ковалевский Д.В., Куликова Н.А., Филиппова О.И., Венедиктов П.С., Полынов В.А. Детоксикация тяжелых металлов, полиароматических углеводородов и пестицидов гумусовыми веществами в водах и почвах // Вода: экология и технология: материалы Международного конгресса. М.: МГУ, 1994. - Т. 4. - С. 1136-1143.

4. Фомин Г.С. Вода. Контроль химической, бактериальной и радиационной безопасности по международным стандартам. - М.: Протектор, 2010. - 1008 с.

5. Bryan N.D., Abrahamsen L., Evans N., Warwick P., Buckau G., Weng L., Van Riemsdijk W.H. The effects of humic substances on the transport of radionuclides: Recent improvements in the prediction of behaviour and the understanding of mechanisms // Applied Geochemistry. - 2012. V. 27. - Iss. 2. - P. 378-389.

6. Frimmel F.H., Huber L. Influence of humic substances on the aquatic adsorption of heavy metals on defined mineral phases // Environment International. - 1996. - V. 22. - № 5. - P. 507-517.

7. Moiseenko T.I., Gashkina N.A., Skjelkvåle B.L., Shalabodov A.D., Khoroshavin V.Y. Water chemistry in small lakes along a transect from boreal to arid ecoregions in european Russia: effects of air pollution and climate change // Applied Geochemistry. - 2013. - V. 28. - P. 69-79.

\title{
BASIC FORMS OF METALS MIGRATION IN THE PRESENCE OF HUMIC SUBSTANCES IN SODA LAKES OF EASTERN TRANSBAIKALIA
}

\author{
I.A. Fedorov, S.V. Borzenko \\ Institute of Natural Resources, Ecology and CryologySBRAS, Chita, Russia.E-mail:fedorowia@gmail.com,svb_64@mail.ru
}

ABSTRACT: Chemical research results and thermodynamic modeling of natural water samples composition taken from soda lakes of Eastern Transbaikalia are considered in the thesis; basic forms of some metals available were determined. It has been determined that minerals, which lake water is in equilibrium with and even supersaturated by them, appeared to be the main barrier against basic cations concentration in lakes considered. The number of metals bound to complexes and their positions in the rows are determined by the level of organic matter, their properties, together with basic geochemical parameters of the environment. 